\title{
RANCANGAN SISTEM INFORMASI LAPORAN DANA BANTUAN PERSONAL PENDIDIKAN MELALUI PROGRAM TANGERANG CERDAS PADA DINAS PENDIDIKAN DAN KEBUDAYAAN KOTA TANGERANG
}

\author{
Radiyanto $^{1}$ \\ Erna Astriyani ${ }^{2}$ \\ Eka Juliyawati ${ }^{3}$ \\ Email : radiyanto@ raharja.info ${ }^{1}, \underline{\text { erna.astriyani@ raharja.info }}{ }^{2}, \underline{\text { eka.juliyawati@ } \text { raharja.info }^{3}}$
}

\begin{abstract}
ABSTRAK
Seiring dengan perkembangan teknologi yang hampir di seluruh bidang bahkan tidak terkecuali dalam laporan dana bantuan personal pendidikan melalui Tangerang Cerdas. Pada perkembangan ini memungkinkan seluruh kegiatan dalam laporan dana bantuan personal melalui Tangerang Cerdas dapat memanfaatkan teknologi informasi. laporan dana bantuan personal pendidikan melalui program Tangerang Cerdas ditujukan pada peserta didik yang kurang mampu untuk menunjang biaya pendidikannya agar satuan pendidikan dapat melakukan kegiatan pendidikan secara teratur dan berkelanjutan. Sistem pada Tangerang Cerdas pada saat ini masih kurang efektif dalam mengontrol pengelolaan laporan anggaran personal dalam pendataan yang dikhawatirkan akan terjadinya pengandaan data. penelitian ini terbatas pada pembahasan mulai dari pencatatan laporan dana bantuan personal pendidikan melalui Tangerang Cerdas sampai menjadi laporan untuk per semester atau tiap 6 (enam) bulannya. Dimana dalam laporan tersebut terdapat data-data peserta didik yang berhak mendapatkan dana bantuan personal melalui Tangerang Cerdas agar tepat sasaran dan tidak terdapat penggandaan data.
\end{abstract}

Kata Kunci: Laporan, Dana Bantuan dan Peserta Didik.

\begin{abstract}
Along with the development of technology that in almost all areas in the report is no exception even personal assistance fund education through Tangerang Cerdas. On this development allows all activities in the statement of personal assistance funds through Tangerang Smart can use information technology. Report personal education grants through programs aimed at the Tangerang Cerdas learners who are less able to support the cost of education so that the educational unit can conduct regular and ongoing education. Intelligent systems in Tangerang today are less effective in controlling the management of personal budget report in data collection is feared to be the duplication data. This study is limited to the discussion of the report from the recording of personal education grants through Tangerang Smart to be a report for each semester or every 6 (six) month. Where in the report are the data of students who are entitled to personal assistance funding through the Tangerang Cerdas for the right target and there is no duplication of data.
\end{abstract}

Keywords: Reports, Personal Assistance Fund and Students. 


\section{PENDAHULUAN}

Seiring dengan perkembangan teknologi yang hampir diseluruh bidang bahkan tidak terkecuali dalam laporan dana bantuan personal pendidikan melalui program Tangerang Cerdas. Pada perkembangan ini memungkinkan seluruh kegiatan dalam laporan dana bantuan personal melalui program Tangerang Cerdas dapat memanfaatkan teknologi informasi. Dimana kebutuhan akan teknologi informasi berhubungan dengan peran dari pengelolaan laporan dana bantuan personal pendidikan melalui program Tangerang Cerdas sebagai program pendidikan yang diperlukan untuk membantu membiayai kegiatan personal selama 12 (dua belas) bulan atau dua semester sebagai bagian dari keseluruhan dana pendidikan yang ditujukan pada peserta didik yang kurang mampu untuk menunjang biaya pendidikannya agar satuan pendidikan dapat melakukan kegiatan pendidikan secara teratur dan berkelanjutan. Saat ini dalam pembuatan laporan dana bantuan masih menggunakan perangkat lunak Ms. Excel, namun proses tersebut belum berjalan secara optimal, sehingga informasi yang di dapat menjadi terhambat pada saat pencarian data.

\section{LANDASAN TEORI}

- Definisi Rancangan Sistem

Rancangan sistem adalah suatu fase dimana diperlukan suatu keahlian perencanaan untuk elemen-elemen komputer yang akan menggunakan sistem baru. Ada dua hal yang perlu diperhatikan dalam perancangan sistem yaitu pemilihan peralatan dan program komputer untuk sistem yang baru (Kristanto, 2008:61).

- Definisi Sistem Informasi

Menurut Eka Pratama (2014:10) Sistem informasi merupakan gabungan dari empat bagian utama. Keempat bagian utama tersebut mencakup perangkat lunak (software), perangkat keras (hardware), infrastruktur, dan Sumber Daya Manusia (SDM) yang terlatih.Keempat bagian utama ini saling berkaitan untuk menciptakan sebuah sistem yang dapat mengolah data menjadi informasi yang bermanfaat. Di dalamnya juga termasuk proses perencanaan, kontrol, koordinasi, dan pengambilan keputusan.

- Definisi Analisa SWOT

Menurut Hendro (2011:289), "Analisa SWOT adalah analisis masalah terhadap kegiatan penting yang sama pentingnya dengan proses pengambilan keputusan itu sendiri”.

\section{PERMASALAHAN}

Prosedur sistem yang berjalan pada saat ini masih menggunakan cara yang manual dimana dalam input data usulan menggunkan perangkat lunak Ms. Excel sehingga sIstem yang berjalan belum optimal dan dapat menghambat dalam pembuatan laporan dana bantuan personal pendidikan.

Berdasarkan latar belakang yang ada, maka dapat dirumuskan permasalahan sebagai berikut:

1. Bagaimana sistem berjalan pada saat ini yang digunakan pada Dinas Pendidikan Dan Kebudayaan Kota Tangerang dalam membuat laporan dana bantuan personal pendidikan melalui program Tangerang Cerdas? 
2. Apa saja yang menjadi kendala pada sistem yang digunakan selama ini pada Dinas Pendidikan?

3. Bagaimana merancang laporan dana bantuan personal pendidikan melalui program Tangerang Cerdas?

\section{LITERATURE REVIEW}

Banyak penelitian yang sebelumnya dilakukan mengenai laporan dana bantuan personal pendidikan. Dalam upaya pengembangan laporan dana bantuan perlu dilakukan studi pustaka sebagai salah satu dari penerapan metode penilitian yang akan dilakukan. Diantaranya adalah menghindari pembuatan ulang serta mengetahui orang lain yang spesifikasinya dan area penelitiannya sama di bidang ini. Beberapa Literature Review tersebut adalah sebagai berikut:

1. Penelitian yang dilakukan oleh Ega Ariesta Ramadhan dengan NIM : 0912464209, 2014 dengan judul "Rancangan Sistem InformasiPenyaluran Dana Bantuan Operasional Sekolah (BOS) Berbasis Web Pada SD Negeri Cimone 4".

Penerapan Teknologi Informasi saat ini telah menyebar hampir di semua bidang tidak terkecuali dalam pengelolaan Dana Operasional Sekolah memungkinkan seluruh kegiatan pengelolaan dana bantuan operasional memanfaatkan teknologi informasi.Kebutuhan akan Teknologi Informasi sangat berhubungan dengan peran dari pengelolaan dana bos sebagai program standar pendidikan yang diperlukan untuk membiayai kegiatan operasi nonpersonalia selama 1 (satu) tahun sebagai bagian dari keseluruhan dana pendidikan agar satuan pendidikan dapat melakukan kegiatan pendidikan secara teratur dan berkelanjutan sesuai dengan Standar Nasional Pendidikan. Dengan dibangunnya Aplikasi Sistem Informasi Manajemen "ASISMEN" Bantuan Operasional Sekolah "BOS", yakni dapat memberikan informasi kepada orang kepala sekolah maupun bendahara sekolah atau lembaga pendidikan mengenai masalah penyaluran KEUANGAN dana BOS tersebut. Agar informasi yang diberikan disajikan dalam bentuk laporan khusus sehingga dapat disajikan secara tepat dan periodik mudah dimengerti dan mudah dalam penggunaannya. Salah satu contohnya adalah penerapan sistem informasi keuangan di perusahaanperusahaan atau lembaga-lembaga lain, begitu juga di SDN Cimone 4 Hasil akhir dari penelitian ini berupa sistem yang dapat menyajikan laporan yang akurat dan uptodate sehingga memenuhi tujuan yang ingin dicapai dalam standar 8 pendidikan nasional yang di tetapkan oleh pemerintah pusat.

2. Penelitian yang dilakukan oleh Rio Ridha Ariestyo, Arna Fariza S.Kom M.Kom, Ira Prasetya Ningrum S.Si MT, 2010 dengan judul "Sistem Informasi Pengelolaan Dana Bantua Operasional Sekolah ( BOS ) Di SMP Surabaya”.

Sistem pelaporan dana Batuan Operasional Sekolah ( BOS ) saat ini masih menggunakan system manual, hal tersebut sering timbul kesalahan yang merepotkan pengelolah BOS harus selalu revisi laporan kepada dinas pendidikan. Pengertian dana BOS sendiri adalah program pemerintah untuk penyediaan pendanaan biaya nonpersonalia bagi satuan pendidikan dasar dan menengah sebagai sarana pelaksanaan program wajib belajar 9 tahun. Program BOS bertujuan untuk membebaskan segala jenis biaya pendidikan bagi seluruh siswa SD, SMP negeri dan swasta di Indonesia dari 
biaya operasional sekolah. Pada proyek akhir ini akan dirancang system informasi pengelolaan dana BOS di SMP Surabaya, dalam bentuk aplikasi web yang menggunakan bahasa pemrograman PHP dan database My SQL. Sistem informasi ini dapat membantu sekolah dalam proses penyusunan rencana anggaran pendapatan belanja sekolah (RAPBS) setiap tahun, dan penyusunan realisasi pelaporan penggunaan dana BOS setiap triwulannya dalam bentuk buku kas umun (BKU) sehingga memudahkan dinas pendidikan dalam pengecakan pelaporan dana bantuan operasional sekolah yang telah disalurkan ke sekolah.

3. Penelitian yang dilakukan oleh Sigit Pribadi, 2007 dengan judul "Sistem Pendukung Keputusan Untuk Pengalokasian Dana Bantuan Langsung Masyarakat Program Penanggulangan Kemiskinan Perkotaan Di Kabupaten Magelang Propinsi Jawa Tengah".

Salah satu program penanggulangan kemiskinan yang diluncurkan pemerintah adalah Program Penanggulangan Kemiskinan di Perkotaan (P2KP), yang dikategorikan sebagai Program Kerja Mandiri (Self Employment Program).P2KP merupakan program pemerintah yang secara substansi berupaya dalam penanggulangan kemiskinan melalui konsep memberdayakan masyarakat dan pelaku pembangunan lokal lainnya. Untuk mendapatkan alokasi dana Bantuan Langsung Masyarakat (BLM) ini, kelompok swadaya masyarakat terlebih dahulu mengajukan usulan kegiatan. Usulanusulan kegiatan tersebut kemudian diverifikasi oleh manajeman P2KP. Usulan yang paling tinggi nilainya diprioritaskan dalam pengalokasian dana BLM. Kriteria- kriteria dan usulan yang begitu banyak menuntut manajemen PKP untuk dapat memperhitungkan manfaat dan resiko dari setiap keputusannya.Penelitian ini berusaha untuk membentuk suatu sistem pendukung keputusan yang diharapkan dapat membantu pengambil keputusan untuk melaksanakan pertimbangannya. Sistem yang dibangun akan memudahkan pengambil keputusan untuk membuat, menghapus, ataupun mengedit model-model penilaian yang ada. Dengan mengetahui model yang paling tepat untuk masing-masing kelompok ataupun usulan, diharapkan pengalokasian dana Bantuan Langsung Masyarakat khususnya di Kabupaten Magelang Propinsi Jawa Tengah dapat diperoleh oleh masyarakat dan wilayah yang benar-benar membutuhkan.

4. Penelitian yang dilakukan oleh Emi Ratna Setiani, Jajang Kusnendar dan Eka Widhi Yunarso, 2010 dengan judul "Sistem Informasi Pendapatan Daerah". Penelitian ini menjelaskan tentang pengembangan SIMPATDA (Sistem Informasi Pendapatan Daerah) yang ada di kota Bandung, bertujuan untuk mengembangkan menu pelaporan yang telah ada dan memberikan transparasi kepada wajib pajak tentang pajak mereka. Simpatda yang digunakan di dipenda kota bandung masih berbentuk aplikasi desktop dan hanya orang-orang tertentu yang dapat mengaksesnya. Simpatda tersebut akan dikembangkan menjadi web based, agar ada lebih dari satu admin yang memasukkan data. Wajib pajak juga dapat mengetahui tentang pajak mereka dari web yang telah disediakan. Penggunaan web based dalam aplikasi ini bertujuan untuk memudahkan dalam pengaksesan sistem, baik oleh pihak dinas pendapatan daerah, maupun oleh wajib pajak. Proyek akhir ini dimulai dengan 
merancang hubungan antar database dan proses bisnis yang terjadi didalam aplikasi. Kemudian dilanjutkan dengan desain tampilan dan pembuatan program.

5. Penelitian yang dilakukan oleh Ahmad Faisol, Febriana Santi Wahyuni dan Mira Orisa, 2012 dengan judul "Pengembangan Sistem Informasi Manajemen Dana Pensiun Pegawai pada PT. Taspen Kantor Cabang Jember".

Penelitian ini akan membahas pengembangan aplikasi sistem informasi untuk mengelola dana pensiun pegawai pada PT Taspen (Persero) Cabang Jember. Aplikasi dikembangkan dengan model clientserver berbasis desktop yang memiliki beberapa fasilitas seperti kemudahan mengakses laporan - laporan serta penginputan data -datanya. Pengembangan aplikasi ini diharapkan dapat menunjang kinerja PT. Taspen (Persero) Cabang Jember dalam mengelola pemberian dana pensiun serta meningkatkan mutu dan pelayanan pada peserta pensiunan itu sendiri di PT. Taspen (Persero) Cabang Jember tersebut.

6. Penelitian yang dilakukan oleh Agustinus Dwi Prasetyo, 2010 dengan judul "Sistem Laporan Penggunaan Dana Bantuan Operasional Sekolah Pada Sekolah Dasar Kabupaten Sleman MelaluiWebsite".

Pengembangan sistem laporan untuk Bantuan Sekolah Dana Operasi di Sleman Kabupaten bertujuan untuk membantu para guru ketika mereka harus mengatur laporan bulanan Bantuan Sekolah Dana Operasi untuk sekolah mereka.Sistem ini diharapkan dapat memecahkan beberapa masalah ketika guru diatur laporan, tidak ada pemahaman seperti laporan Format oleh pemerintah dan informasi akuntansi yang terbatas, sebagian besar guru tidak mampu mengoperasikan komputer sebagai alat kerja mereka. Ada tiga input dasar sehari-hari seperti catatan pengeluaran, data rekening bank dan data pengeluaran pajak. Dan sistem berharap bisa memecahkan masalah pengaturan laporan.Ada tujuh jenis laporan yang harus dibuat seperti kas Umum (tunai untuk umum bertujuan), kas tunai (cash untuk langsung pembayaran), pajak, transaksi perbankan, kapasitas penyerapan dan rincian pengeluaran realisasi untuk setiap tiga bulan.Selama waktu, guru mengatur laporan secara manual. Guru diatur oleh data catatan harian belanja, data rekening bank dan data pengeluaran pajak. Dan pertanyaan terbesar adalah bagaimana mengembangkan sistem untuk membuat guru lebih mudah untuk melakukan pekerjaan mereka?Untuk proyek terakhir, penulis mencoba untuk menganalisis sistem laporan sebelumnya.Satu dari bertujuan untuk mengetahui tentang data laporan saluran. Data membantu penulis untuk memahami sistem sebelumnya sehingga dapat dipengaruhi untuk sistem baru yang akan menyarankan untuk departemen pendidikan Kabupaten Sleman sebagai pelengkap dari sistem sebelumnya.

\section{PEMECAHAN MASALAH}

Untuk mengatasi permasalahan yang ada pada sistem yang berjalan, maka alternatif pemecahan masalah yang dilakukan adalah dengan merancang, membangun dan menyediakan suatu sistem informasi laporan dana bantuan personal melalui Tangerang Cerdas berbasis web untuk mempermudah para pegawai Dinas 
Pendidikan dan Kebudayaan Kota Tangerang dalam proses pembuatan laporan.

$$
\text { Pada pemecahan masalah }
$$
menggunakan metode analisa SWOT (Strengths, Weakness, Opportunities, Threats) adalah suatu metode yang digunakan untuk melihat kondisi di Dinas Pendidikan dan Kebudayaan Kota Tangerang secara internal yang kemudian dijadikan indikator untuk mengetahui kekuatan, kelemahan, peluang dan ancaman sehingga dapat membantu dalam pembuatan keputusan.

\section{UML (Unified Modeling Language )}

Menurut Nugroho (2010:6), "UML (Unified Modeling Language) adalah bahasa pemodelan untuk sistem atau perangkat lunak yang berparadigma (berorientasi objek)." Pemodelan (modeling) sesungguhnya digunakan untuk penyederhanaan permasalahanpermasalahan yang kompleks sedemikian rupa sehingga lebih mudah dipelajari dan dipahami.

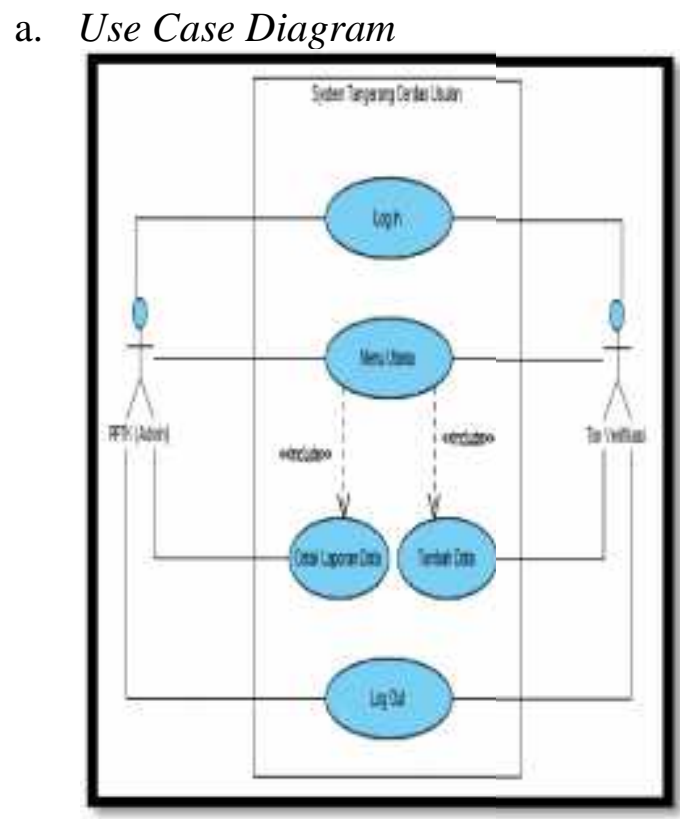

Gambar 1.Use Case DiagramSistem Tangerang Cerdas b. Activity Diagram

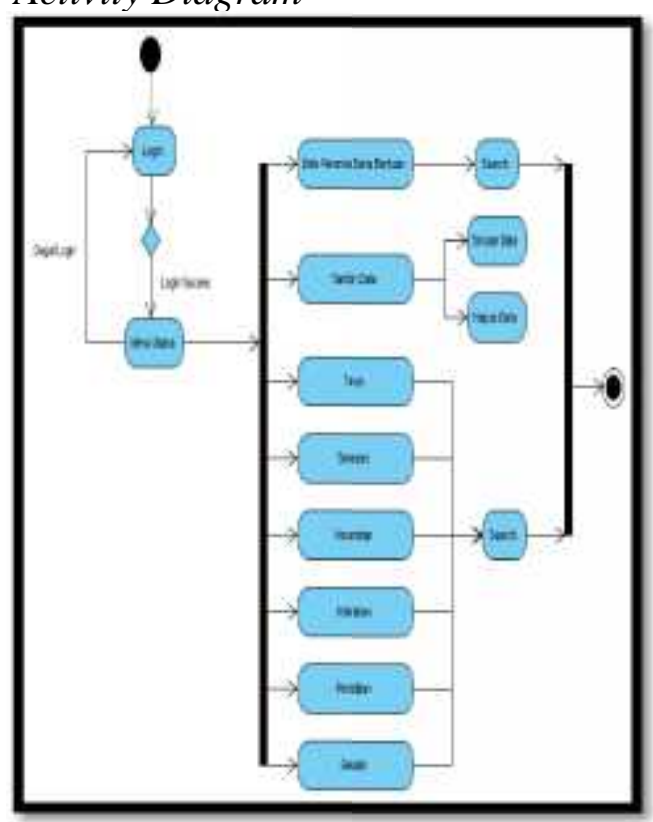

Gambar 2.Activity Diagram Sistem Tangerang Cerdas

c. Sequence Diagram

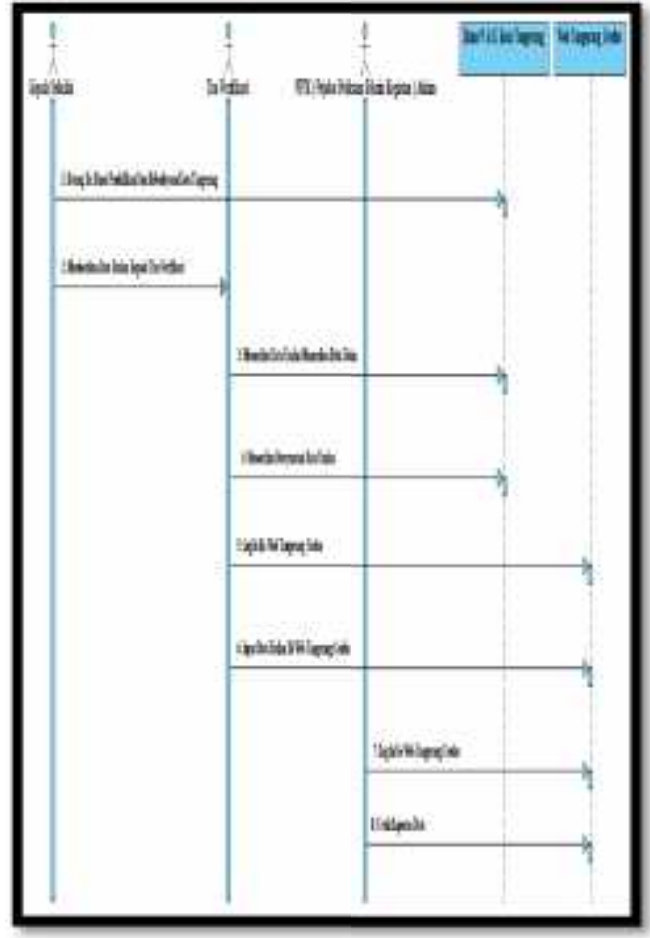

Gambar 3.Sequence Diagram Sistem Tangerang Cerdas 
d. State Machine Diagram

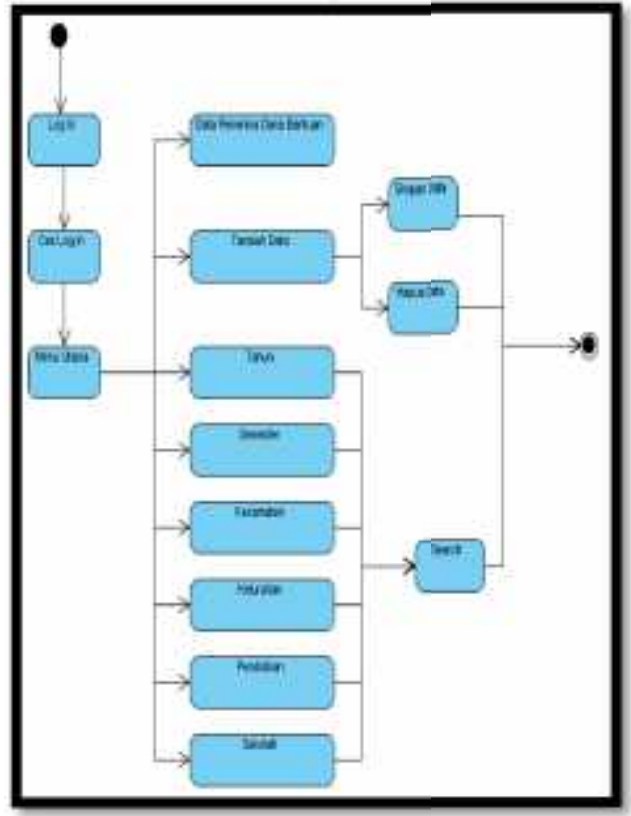

Gambar 4.State Machine Diagram Sistem Tangerang Cerdas

e. Class Diagram

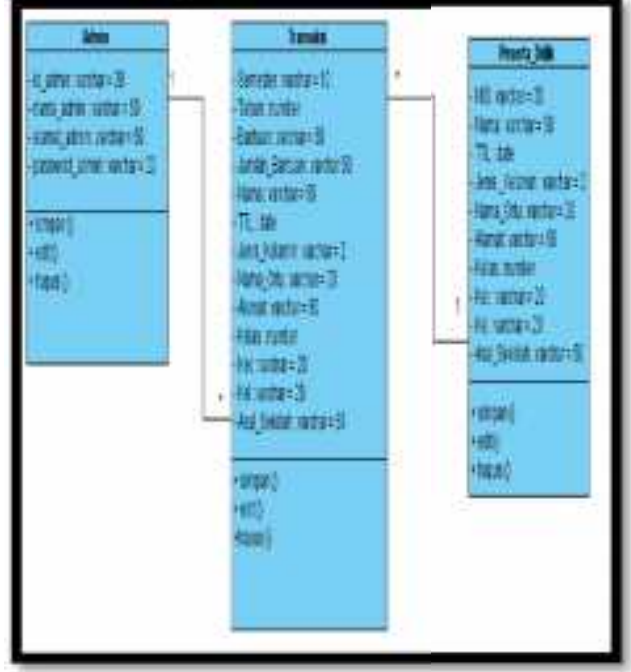

Gambar 5.Class Diagram Sistem Tangerang Cerdas

\section{IMPLEMENTASI}

a. Tampilan Menu Login

Pada tampilan ini admin harus melakukan Log In pada saat melakukan kegiatan yang berhubungan dengan laporan dana bantuan personal pendidikan melalui program Tangerang Cerdas.

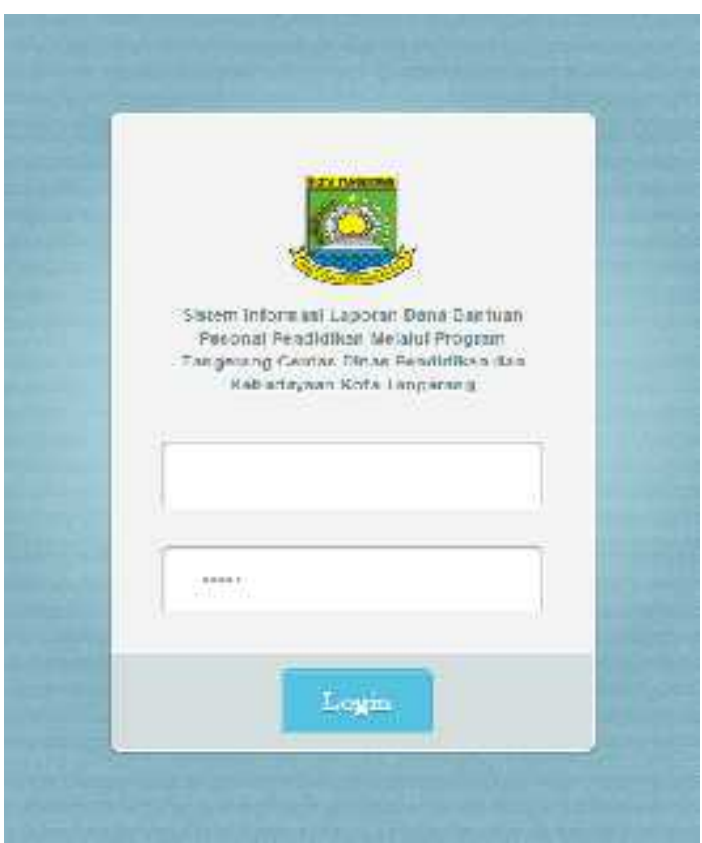

Gambar 6. Tampilan Menu Login

b. Tampilan Menu Utama

Pada tampilan menu utama ini terdapat jumlah data penerima dana bantuan melalui Tangerang Cerdas pada tahun dimana admin melakukan kegiatan input data penerima dana bantuan.

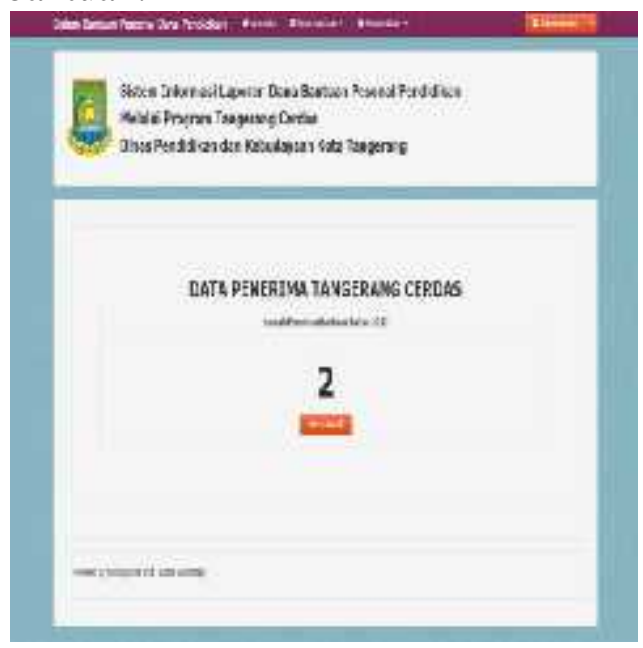

Gambar 7. Tampilan Menu Utama 
c. Tampilan Data Bantuan

Pada tampilan data bantuan ini terdapat data-data peserta didik yang sudah di input oleh admin untuk mendapatkan dana bantuan personal melalui Program Tangerang Cerdas.

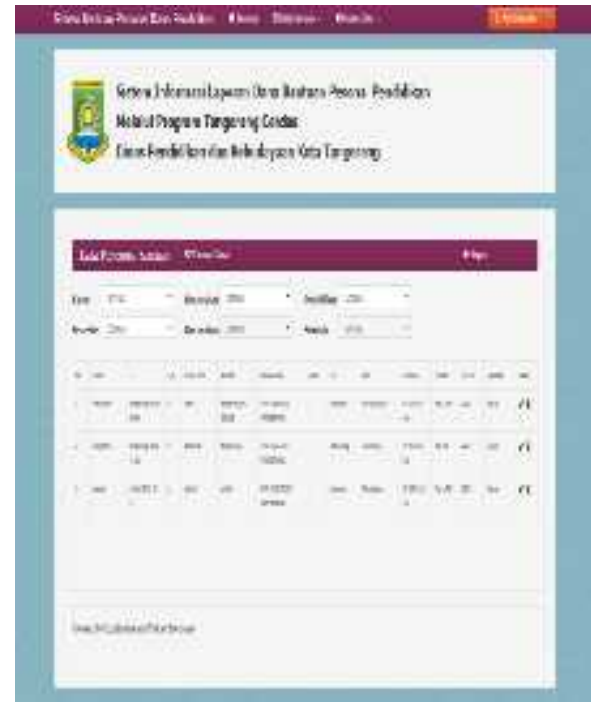

Gambar 8. Tampilan Data Bantuan

d. Tampilan Data Bantuan Filter

Pada tampilan data bantuan filter ini admin dapat mencari data yang dibutuhkan yaitu pencarian data dapat di cari berdasarkan, tahun, semester, kecamatan, kelurahan, sekolah dan jenjang pendidikan.

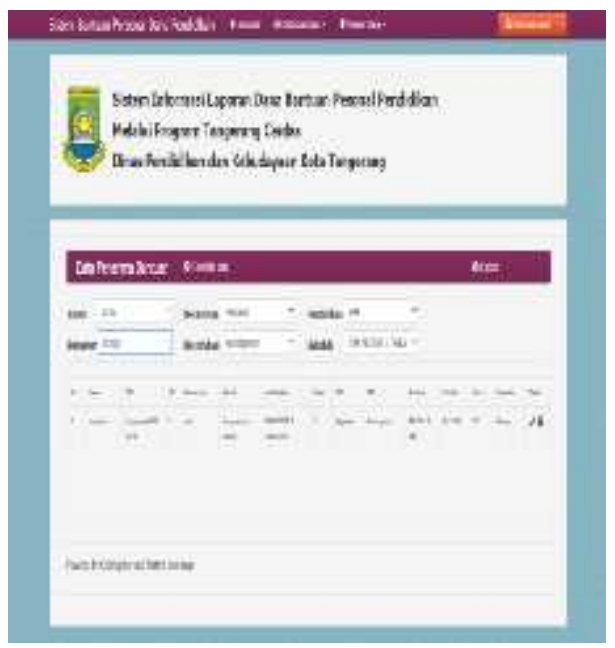

Gambar 9. Tampilan Data Bantuan Filter e. Tampilan Input Data Peserta Didik Penerima Dana Bantuan

Pada tampilan input peserta didik penerima dana bantuan melalui program Tangerang Cerdas yang sudah di periksa data usulannya oleh Tim Verifikasi maka data usulan siap untuk di input pada sistem.

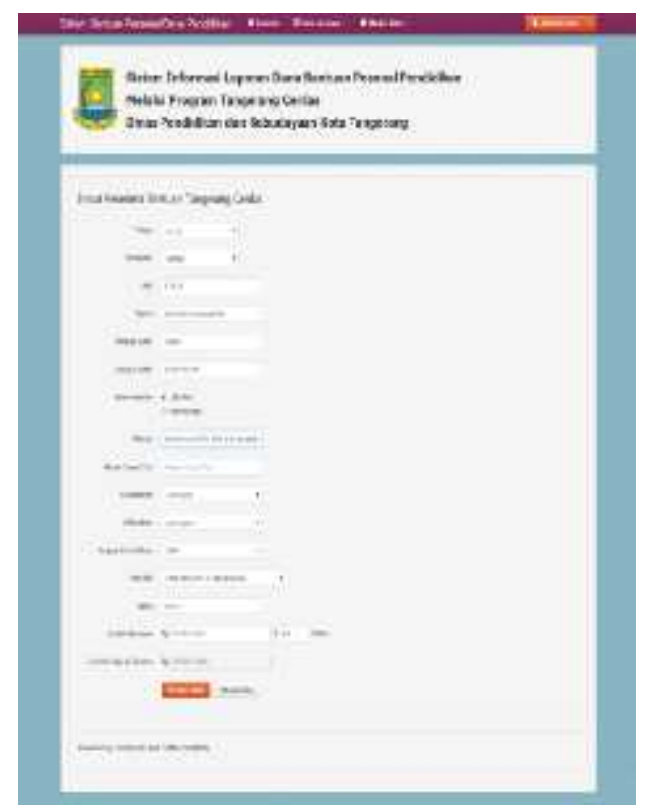

Gambar 10. Tampilan Input Data Peserta Didik Penerima Dana Bantuan

\section{KESIMPULAN}

Berdasarkan dari uraian diatas dapat disimpulkan bahwa laporan dana bantuan personal pendidikan melalui Program Tangerang Cerdas merupakan metode untuk mempercepat waktu proses input data, pencarian data dan pembuatan laporan dana bantuan.Dimana kegiatan yang dilakukan sudah terkomputerisasi dngan baik. Sehingga data yang di inputkan menjadi lebih keakuratan dalam pembuatan laporan, tidak terjadi penggandaan data dan meningkatkan kinerja. 


\section{DAFTAR PUSTAKA}

1. Kristanto, Andi. 2008. PerancanganSistem Informasi dan Aplikasinya. Edisi Revisi. Cet. 1. Yogyakarta: Gava Media.

2. Eka Pratama, I.P.A. 2014. Sistem Informasi dan Implementasinya. Bandung : Informatika.

3. Hendro. 2011. Dasar-dasar Kewirausahaan. Jakarta: Erlangga.

4. Ega Ariesta Ramadhan. 2014. Rancangan Sistem InformasiPenyaluran Dana Bantuan Operasional Sekolah (BOS)Berbasis Web Pada SD Negeri Cimone 4.

5. Rio Ridha Ariestyo, Arna Fariza S.Kom M.Kom, Ira Prasetya Ningrum S.Si MT, 2010. Sistem Informasi Pengelolaan Dana Bantua Operasional Sekolah ( BOS ) Di SMP Surabaya.

6. Nugroho, Adi. 2010. Rekayasa Perangkat Lunak Menggunakan UML \& Java. Yogyakarta: Andi.

7. Sigit Pribadi, 2007. Sistem Pendukung Keputusan Untuk Pengalokasian Dana Bantuan Langsung Masyarakat Program Penanggulangan Kemiskinan Perkotaan Di Kabupaten Magelang Propinsi Jawa Tengah.

8. Emi Ratna Setiani, Jajang Kusnendar dan Eka Widhi Yunarso, 2010. Sistem Informasi Pendapatan Daerah.

9. Ahmad Faisol, Febriana Santi Wahyuni dan Mira Orisa, 2012. Pengembangan Sistem Informasi Manajemen Dana Pensiun Pegawai pada PT. Taspen Kantor Cabang Jember.

10. Agustinus Dwi Prasetyo, 2010. Sistem Laporan Penggunaan Dana Bantuan Operasional Sekolah Pada Sekolah Dasar Kabupaten Sleman MelaluiWebsite. 